\title{
ARTICLE
}

\section{Recent activities on neutron standardization in Japan}

\author{
Hideki HARANO*, Tetsuro MATSUMOTO, Jun NISHIYAMA, Akihiko MASUDA, Akira URITANI, Katsuhisa KUDO \\ National Metrology Institute of Japan (NMIJ), National Institute of Advanced Industrial Science and Technology (AIST), \\ Tsukuba, Ibaraki 305-8568 Japan
}

\begin{abstract}
NMIJ provides national standards on neutron fluence as well as neutron emission rate in Japan. The neutron fluence standards are established for thermal neutrons, monoenergetic neutrons at seven energies from $24 \mathrm{keV}$ to $14.8 \mathrm{MeV}$, radionuclide-source neutrons from ${ }^{252} \mathrm{Cf}$ and ${ }^{241} \mathrm{Am}-\mathrm{Be}$. The neutron emission standards are provided for these radionuclide sources. These are basically prepared in accordance with ISO 8529-1. Worldwide consistency of the standards has been supported by participating in key comparisons organized by BIPM. NMIJ issues calibration certificates accepted worldwide within the range specified in our calibration and measurement capabilities listed in the BIPM web page. The development of the $19 \mathrm{MeV}$ neutron field is in progress to complete standardization in 2011. The radionuclide-source neutron fluence standards were extended in 2008 so that calibrations are also available in terms of ambient/personal dose equivalent. The Japan calibration service system has launched to improve the traceability of neutron measurement in Japan. A new thermal neutron calibration field is developing with a guided beam at the research reactor JRR-3M of JAEA. Aiming at the establishment of the 20-100 MeV high-energy neutron standard, comparison studies are currently being conducted between the cyclotron facilities TIARA of JAEA and CYRIC of the Tohoku University.
\end{abstract}

\section{KEYWORDS: neutron standard, neutron fluence, dose equivalent, emission rate, key comparison, mutual} recognition arrangement, traceability, Japan calibration service system

\section{Introduction}

Neutron standards play an important role in securing the reliability of sensitivities of neutron detectors and intensities of neutron sources. Our laboratory provides national standards on neutron fluence $\left(\mathrm{cm}^{-2}\right)$ (or fluence rate $\left(\mathrm{cm}^{-2} \mathrm{~s}^{-1}\right)$ ) as well as neutron emission rate $\left(\mathrm{s}^{-1}\right)$ in Japan. We report the present status and recent activities of these neutron standards.

\section{Neutron Standards in Japan}

Table 1 summarizes the current lineup of the neutron standards in Japan. These are basically prepared in accordance with ISO 8529-1 ${ }^{1}$. Figure 1 shows the irradiation room the monoenergetic and radionuclide-source neutrons. The dimensions of the room are $11.5 \mathrm{~m} \times 11.5 \mathrm{~m}$ $\times 11.5 \mathrm{~m}$. Neutron source assemblies and measurement instruments are placed on an aluminum-grating floor supported at mid-height of the room to reduce room-return neutrons. Figure 2 shows the graphite pile used in the calibrations of the thermal neutron fluence and the neutron emission rate from radionuclide-sources. Worldwide consistency of these neutron standards has been supported by participating in key comparisons ${ }^{2)}$ organized by the section III (neutron measurements) of the consultative committee for ionizing radiation (CCRI) of the international committee of weights and measures (CIPM) of the international bureau of weights and measures (BIPM). Currently we are participating in the key comparison CCRI(III)-K8 on thermal neutron fluence measurements.
The monoenergetic neutron fluence standards at $2.5 \mathrm{MeV}$, 8.0 $\mathrm{MeV}$ and $24 \mathrm{keV}$ were developed recently and calibration services respectively commenced in 2007, 2008 and 2009. The development of the $19 \mathrm{MeV}$ monoenergetic neutron fluence standard is in progress and calibration services will commence in 2011. Our calibration services on the neutron fluence from bare ${ }^{252} \mathrm{Cf}$ and ${ }^{241} \mathrm{Am}$-Be sources were extended in 2008 so that calibrations are also available in terms of ambient/personal dose equivalent. Neutron fluence is converted to ambient/personal dose equivalent using the conversion coefficients given in ISO 8529-33). To take account of uncertainties in the fluence spectrum, we introduce $1 \%$ for ${ }^{252} \mathrm{Cf}$ and $4 \%$ for ${ }^{241} \mathrm{Am}$-Be as relative uncertainties $(k=1)$ of the conversion coefficient according to the recommendation of ISO $8529-2^{4)}$.

\section{Neutron Fluence Standard at $2.5 \mathrm{MeV}$}

The Cockcroft-Walton accelerator is used to produce the 14.8 $\mathrm{MeV}$ neutrons to the 90 degree direction by the $\mathrm{D}(\mathrm{d}, \mathrm{n})^{3} \mathrm{He}$ reaction, where a $230 \mathrm{keV}$ deuteron beam impinged on a target consisting of a $250 \mathrm{mg} / \mathrm{cm}^{2}$ deuterium-titanium layer evaporated on a $0.5 \mathrm{~mm}$ thick copper backing. The target is inclined at 45 degrees with respect to the deuteron beam axis. The neutron fluence is determined using a proton recoil neutron detector called thick radiator (TR) detector. The TR detector consists of a $0.5 \mathrm{~mm}$ thick polyethylene radiator disk mounted in front of a silicon surface barrier detector ${ }^{9}$. 
Table 1 Lineup of the neutron standards in Japan.

\begin{tabular}{|c|c|c|c|}
\hline Quantity & Conditions & Comments & $\begin{array}{l}\text { Reference } \\
\text { Standard }\end{array}$ \\
\hline \multirow{10}{*}{$\begin{array}{l}\text { Neutron fluence } \\
\qquad\left(\mathrm{cm}^{-2}\right)\end{array}$} & Thermal & $\begin{array}{l}\text { Neutrons inside or outside of the graphite pile with the } \\
{ }^{241} \mathrm{Am}-\mathrm{Be} \text { standard source at the center }{ }^{1,2)} \text {. }\end{array}$ & $\begin{array}{l}\text { Gold foil } \\
\text { activation }\end{array}$ \\
\hline & $24 \mathrm{keV}$ & $\begin{array}{l}{ }^{7} \mathrm{Li}(\mathrm{p}, \mathrm{n}){ }^{7} \mathrm{Be} \text { neutrons from a thick lithium target } \\
\text { monochromized by iron resonant filtering }{ }^{7)} \text {. }\end{array}$ & $\begin{array}{l}{ }^{3} \text { He proportional } \\
\text { counter }\end{array}$ \\
\hline & $144 \mathrm{keV}$ & \multirow{2}{*}{$\begin{array}{l}{ }^{7} \mathrm{Li}(\mathrm{p}, \mathrm{n})^{7} \mathrm{Be} \text { neutrons using the Van de Graaff } \\
\text { accelerator }{ }^{8)} \text {. }\end{array}$} & \multirow{2}{*}{$\begin{array}{l}\mathrm{H}_{2} \text { proportional } \\
\text { counter }\end{array}$} \\
\hline & $565 \mathrm{keV}$ & & \\
\hline & $2.5 \mathrm{MeV}$ & $\begin{array}{l}\mathrm{D}(\mathrm{d}, \mathrm{n})^{3} \mathrm{He} \text { neutrons using the Cockcroft-Walton } \\
\text { accelerator }^{9} \text {. }\end{array}$ & \multirow{2}{*}{$\begin{array}{l}\text { Thick radiator } \\
\text { detector }\end{array}$} \\
\hline & $5.0 \mathrm{MeV}$ & $\begin{array}{l}\mathrm{D}(\mathrm{d}, \mathrm{n})^{3} \mathrm{He} \text { neutrons using the Van de Graaff } \\
\text { accelerator }^{8} \text {. }\end{array}$ & \\
\hline & $8.0 \mathrm{MeV}$ & $\begin{array}{l}{ }^{9} \mathrm{Be}(\alpha, \mathrm{n}){ }^{12} \mathrm{C} \text { neutrons using the Van de Graaff } \\
\text { accelerator }{ }^{10,11)} \text {. }\end{array}$ & $\begin{array}{l}\text { dE-E thick radiator } \\
\text { detector }\end{array}$ \\
\hline & $14.8 \mathrm{MeV}$ & $\begin{array}{l}\mathrm{T}(\mathrm{d}, \mathrm{n})^{4} \mathrm{He} \text { neutrons using the Cockcroft-Walton } \\
\text { accelerator }^{8)} \text {. }\end{array}$ & $\begin{array}{c}\text { Associated particle } \\
\text { detector }\end{array}$ \\
\hline & ${ }^{252} \mathrm{Cf}$, bare & \multirow{2}{*}{$\begin{array}{l}\text { Determined by considering the anisotropy in neutron } \\
\text { emission from sources }{ }^{1} \text {. }\end{array}$} & \multirow{6}{*}{$\begin{array}{l}{ }^{241} \text { Am-Be standard } \\
\text { source }\end{array}$} \\
\hline & ${ }^{241} \mathrm{Am}-\mathrm{Be}$, bare & & \\
\hline \multirow{2}{*}{$\begin{array}{c}\text { Personal/Ambient } \\
\text { dose equivalent } \\
\text { (Sv) }\end{array}$} & ${ }^{252} \mathrm{Cf}$, bare & \multirow{2}{*}{$\begin{array}{l}\text { Converted from the neutron fluence using the conversion } \\
\text { coefficients given in ISO } 8529-3^{3)} \text {. }\end{array}$} & \\
\hline & ${ }^{241} \mathrm{Am}-\mathrm{Be}$, bare & & \\
\hline \multirow{2}{*}{$\begin{array}{l}\text { Neutron emission } \\
\quad \text { rate }\left(\mathrm{s}^{-1}\right)\end{array}$} & ${ }^{252} \mathrm{Cf}$, bare & \multirow{2}{*}{$\begin{array}{l}\text { Relative calibration to the standard source by measuring } \\
\text { the thermal neutron fluence rate in the graphite pile }{ }^{12)} \text {. }\end{array}$} & \\
\hline & ${ }^{241} \mathrm{Am}-\mathrm{Be}$, bare & & \\
\hline
\end{tabular}

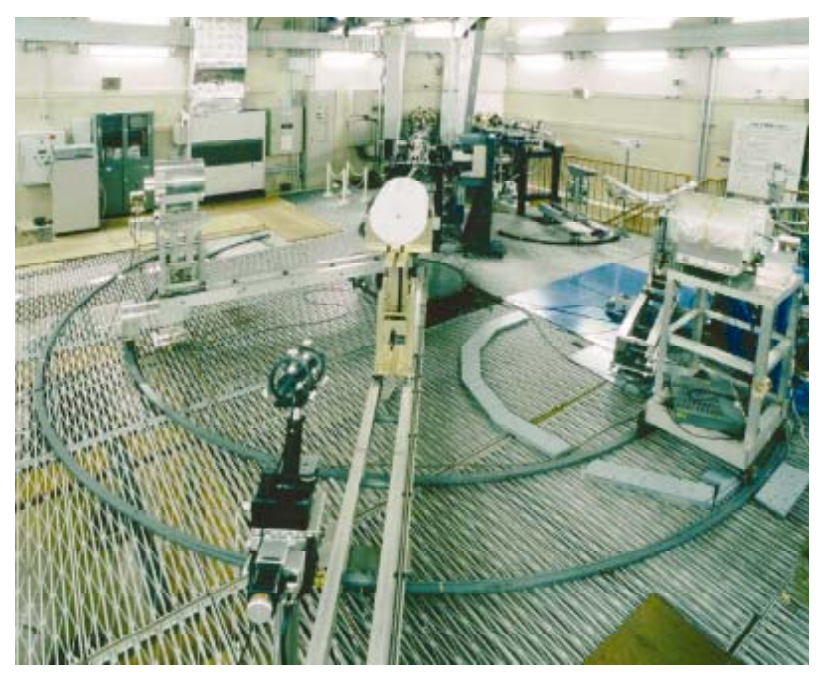

Figure 1 Standard fast neutron irradiation field.

\section{Neutron Fluence Standard at $8.0 \mathrm{MeV}$}

The 8.0 MeV neutron fluence standard will be helpful for users who are interested in acquiring supplementary data on the response of neutron-measuring devices between 5.0 and 14.8 MeV, the ISO 8529-1 recommended energies for calibration.

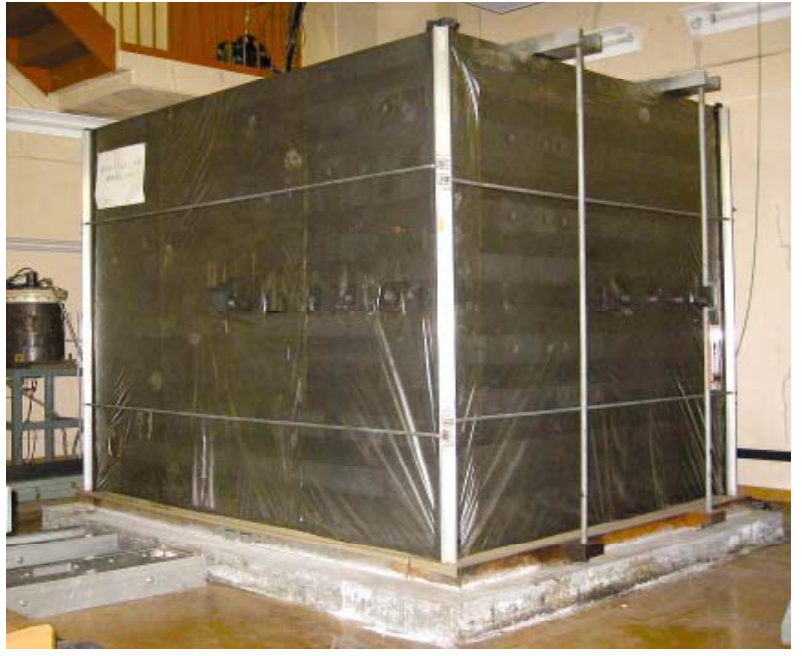

Figure 2 Standard thermal neutron irradiation field.

The $8 \mathrm{MeV}$ neutrons are produced in the ${ }^{9} \mathrm{Be}(\alpha, \mathrm{n}){ }^{12} \mathrm{C}$ reaction and accompanied by $3.5 \mathrm{MeV}$ neutrons where 2.4 $\mathrm{MeV}^{4} \mathrm{He}^{+}$ions from the Van de Graaff accelerator impinges on a target composed of a $500 \mathrm{~nm}$ thick beryllium layer evaporated on a $0.5 \mathrm{~mm}$ thick tantalum backing. The 8 $\mathrm{MeV}$ and $3.5 \mathrm{MeV}$ neutrons are respectively generated by 
the transition to the ground and first excited states of their residual ${ }^{12} \mathrm{C}$ nuclei and the contribution of the $3.5 \mathrm{MeV}$ neutrons will be subtracted in actual calibrations ${ }^{10)}$. The neutron fluence is determined using the TR detector with a dE-E configuration, incorporating a thin transmission-type silicon detector (dE) with a $50 \mathrm{~mm}$ depletion depth sandwiched between a $1 \mathrm{~mm}$ thick polyethylene radiator disk and a silicon detector (E) with a $2 \mathrm{~mm}$ depletion depth. Coincidence counting between the $\mathrm{dE}$ and $\mathrm{E}$ detectors suppresses measurement of events caused by the unwanted reactions such as $\operatorname{Si}(n, p)$ and $\operatorname{Si}(n, \alpha)^{11)}$.

\section{Neutron Fluence Standard at $24 \mathrm{keV}$}

ISO 8529-1 gives two production methods of $24 \mathrm{keV}$ neutrons: iron/aluminum-filtered neutrons from nuclear reactors and accelerator-produced neutrons from the ${ }^{45} \mathrm{Sc}(\mathrm{p}, \mathrm{n}){ }^{45} \mathrm{Ti}$ reaction. The $24 \mathrm{keV}$ neutron fluence standard has been established however using a new method that we proposed to generate $24 \mathrm{keV}$ neutrons by iron filtering of accelerator-produced neutrons from the ${ }^{7} \mathrm{Li}(\mathrm{p}, \mathrm{n})^{7} \mathrm{Be}$ reaction ${ }^{7)}$.

A $1.890 \mathrm{MeV}$ proton beam from the Van de Graaff accelerator impinges on the thick lithium target consisting of an approximately $20 \mu \mathrm{m}$ thick lithium layer evaporated on a $0.5 \mathrm{~mm}$ thick tantalum backing. Neutrons from 8 to $65 \mathrm{keV}$ are then produced within 30 degrees with respect to the incident beam direction, which are successively injected onto a postplaced iron filter with $80 \mathrm{~mm}$ thick. While the iron/aluminum-filtered reactor neutrons normally have several polychromatic components because iron-56 has several deep minima in the total cross section such as 24,73 , 82 and $137 \mathrm{keV}$, the present configuration allows monochromatic neutrons at $24 \mathrm{keV}$ to transmit though the iron filter.

The neutron fluence is determined using a ${ }^{3} \mathrm{He}$ cylindrical proportional counter with a $0.5-\mathrm{mm}$ thick $\mathrm{Cd}$ cover, which was calibrated with the thermal neutron fluence standard. The neutron flux is 15 times larger than that available from the ${ }^{45} \mathrm{Sc}(\mathrm{p}, \mathrm{n})^{45} \mathrm{Ti}$ reaction neutron source ${ }^{7,13)}$

\section{CIPM Mutual Recognition Arrangement}

The CIPM mutual recognition arrangement (MRA) ${ }^{14)}$ provides a framework associated with the mutual recognition between signatories for the calibration and measurement certificates issued by national metrology institutes and requires to the participants as follows. The national standards must be operated with the quality management systems conforming to ISO/IEC $17025^{15}$. Every five years, the conformity assessment and technical peer review are conducted on site respectively by an accreditation body fulfilling the requirements of ISO/IEC 17011 ${ }^{16)}$ and experts from major foreign national metrology institutes. The technical competence of the participants is reviewed based mainly on the results of the past key comparisons.

In 2003 and 2008, the neutron standards in Japan underwent the first and second conformity assessment and technical peer review. The quality management systems were assessed by the International Accreditation Japan (IAJapan) of the National Institute of Technology and Evaluation (NITE) under the ASNITE Accreditation Program $^{17)}$. The ISO/IEC 17025 accreditation was acquired in 2004 and updated in 2009. In 2006, the approved calibration and measurement capabilities (CMCs) were published in the web-page of the BIPM ${ }^{18)}$. The certificates issued on the neutron standards can be accepted worldwide within the range specified in the CMCs in the framework of the CIPM MRA.

\section{Japan Calibration Service System}

The Japan calibration service system $(\mathrm{JCSS})^{19)}$ consists of the national standards provision system and the calibration laboratory accreditation system introduced by the amended measurement act enforced in 1993. In the national measurement standards provision system, the ministry of economy, trade and industry (METI) designates national primary standards and NMIJ calibrates the reference standards of accredited calibration laboratories (i.e. secondary standards) with national primary standards. In the calibration laboratory accreditation system, calibration laboratories are assessed and accredited as accredited calibration laboratories to meet the requirements of the measurement act, relevant regulations and ISO/IEC 17025. Calibration laboratories are also required to periodically take assessment as well as proficiency testing. Calibration certificates with the JCSS symbol issued by accredited calibration laboratories assure the traceability to National Measurement Standards as well as a laboratory's technical and operational competence and are acceptable in the world through the MRA of the international laboratory accreditation cooperation (ILAC) ${ }^{20)}$ and the Asia pacific laboratory accreditation cooperation (APLAC) ${ }^{21)}$.

We are renovating the traceability of neutron measurement in Japan by starting calibration services based on JCSS. In 2008, JCSS commenced on the monoenergetic neutron fluence standards at $144 \mathrm{keV}, 565 \mathrm{keV}, 5.0 \mathrm{MeV}$ and 14.8 $\mathrm{MeV}$. METI designated the primary standards and the secondary standards in the METI notifications. Bonner spheres were specified as the secondary standards. Now one calibration laboratory intends to be a JCSS accredited calibration laboratory and plans to apply to IAJapan for accreditation. In 2009, NMIJ performed the first JCSS calibration of the specified secondary standard of the calibration laboratory.

According to our original planning, JCSS is scheduled to start on thermal neutron fluence rate and neutron emission rate in 2009 and 2011, respectively. In response to industrial needs, we decided to start JCSS calibration services on source-emitted neutron fluence for ${ }^{252} \mathrm{Cf}$ and ${ }^{241} \mathrm{Am}-\mathrm{Be}$ as well. We changed the schedule so that JCSS will start on source-emitted neutron fluence in 2009 and on thermal neutron fluence rate and neutron emission rate in 2011. JCSS on source-emitted neutron fluence was deliberated and approved in the METI measurement administration council in 2008. METI will designate the primary standards and the secondary standards in METI notifications soon. Flat 
response neutron detectors such as long counters will be specified as the secondary standards. So far, two calibration laboratories intend to obtain a JCSS accreditation on source-emitted neutron fluence.

\section{Conclusion}

We reported the present status of the neutron standards in Japan and the recent activities including the establishment of new neutron standards, the CIPM MRA and the JCSS. We are also taking another step forward to develop new neutron calibration fields in response to industrial needs. An intense thermal neutron calibration field up to $5 \times 10^{8} \mathrm{~cm}^{-2} \mathrm{~s}^{-1}$ is being under development with a thermal neutron guided beam at the research reactor JRR-3M of the Japan Atomic Energy Agency (JAEA) ${ }^{22)}$. There is also a need for neutron fluence standards in the $20-100 \mathrm{MeV}$ energy region since neutrons having these energies are very important for radiation protection against cosmic rays and around the facilities producing high intensity energetic neutrons such as $\mathrm{J}_{-P A R C}{ }^{23)}$. There are several high-energy neutron facilities in Japan, which have been used in many studies, including nuclear data measurements and shielding benchmark experiments. High-energy neutron fields at cyclotron facilities TIARA ${ }^{24)}$ and CYRIC $^{25)}$ are promising candidates for standard fields and comparison studies are currently being conducted between these two facilities.

\section{References}

1) ISO 8529-1:2001, Reference neutron radiations - Part 1: Characteristics and methods of production.

2) See http://kcdb.bipm.org/AppendixB/.

3) ISO 8529-3:1998, Reference neutron radiations - Part 3: Calibration of area and personal dosimeters and determination of response as a function of energy and angle of incidence.

4) ISO 8529-2:2000, Reference neutron radiations - Part 2: Calibration fundamentals of radiation protection devices related to the basic quantities characterizing the radiation field.

5) K. Kudo, N. Takeda, S. Koshikawa, H. Toyokawa, H. Ohgaki, M. Matzke, "Photon spectrometry in thermal neutron standard field," Nucl. Instr. and Meth. A, 476, 213-217 (2002).

6) K. Kudo, N. Takeda, A. Fukuda, "Measurement of $\gamma$-ray dose in a thermal neutron field by using a ${ }^{3} \mathrm{He}$-filtered GM counter," IEEE Trans. Nucl. Sci., 43[3], 1851-1854 (1996).

7) T. Matsumoto, H. Harano, J. Nishiyama, K. Kudo, A. Uritani, "Novel generation method of $24-\mathrm{keV}$ monoenergetic neutrons using accelerators," Proc. of 20th International Conference on the Application of Accelerators in Research and Industry (CAARI2008), Fort Worth, Texas U.S.A., Aug. 10-15, 2008, AIP Conference Proceedings, Volume 1099, ISBN 978-0-7354-0633-9, 924-927 (2009).

8) J. Chen, Z. Wang, C. Rong, G. Lovestam, A. Plompen, N. Puglisi, D. M. Gilliam, C. M. Eisenhauer, J. S. Nico, M. S. Dewey, K. Kudo, A. Uritani, H. Harano, N. Takeda, D. J. Thomas, N. J. Roberts, A. Bennett, P. Kolkowski, N. N. Moisseev, I. A. Kharitonov, S. Guldbakke, H. Klein, R. Nolte, D. Schlegel, "International key comparison of neutron fluence measurements in mono-energetic neutron fields: CCRI(III)-K10," Metrologia, 44, 06005 (2007).

9) H. Harano, T. Matsumoto, T. Shimoyama, T. Hata, K. Moriyama, K. Kudo, S. Miwa, T. Koyamada, A. Uritani, "Characterization of the $3 \mathrm{MeV}$ Neutron Field for the Monoenergetic Fast Neutron Fluence Standard at the National Metrology Institute of Japan," Proc. of International Workshop on Fast Neutron Detectors (FNDA2006), Cape Town, South Africa, Apr. 3-6, 2006, PoS017 (2006).

10) T. Shimoyama, H. Harano, T. Matsumoto, K. Moriyama, T. Hata, K. Kudo, T. Koyamada, A. Uritani, "Development of the fast neutron standard using a $\operatorname{Be}(\alpha, n)$ reaction at the National Metrology Institute of Japan," Radiat. Prot. Dosim., 126, 130-133 (2007).

11) H. Harano, T. Matsumoto, J. Nishiyama, A. Uritani, K. Kudo, "Accelerator-based Neutron Fluence Standard of the National Metrology Institute of Japan," Proc. of 20th international Conference on the Application of Accelerators in Research and Industry (CAARI2008), Fort Worth, Texas U.S.A., Aug. 10-15, 2008, AIP Conference Proceedings, Volume 1099, ISBN 978-0-7354-0633-9, 915-918 (2009).

12) H. Harano, T. Matsumoto, T. Shimoyama, Y. Sato, A. Uritani, Y. Hino, K. Kudo, T. Michikawa, "Convenient method of relative calibration of the neutron source emission rate between different source type," IEEE Trans. Nucl. Sci., 53, 3, 1413-1417 (2006).

13) T. Matsumoto H. Harano, T. Shimoyama, K. Kudo, A. Uritani, "Characterisation of kilo electron volt neutron fluence standard with the ${ }^{45} \mathrm{Sc}(\mathrm{p}, \mathrm{n}){ }^{45} \mathrm{Ti}$ reaction at NMIJ," Radiat. Prot. Dosim., 126, 1550-158 (2007) .

14) See http://www.bipm.org/en/cipm-mra/.

15) ISO/IEC 17025:2005, General requirements for the competence of testing and calibration laboratories.

16) ISO/IEC 17011:2004, Conformity assessment - General requirements for accreditation bodies accrediting conformity assessment bodies.

17) See http://www.iajapan.nite.go.jp/asnite/en/index.html.

18) See http://kcdb.bipm.org/AppendixC/.

19) See http://www.iajapan.nite.go.jp/jcss/en/index.html.

20) See http://www.ilac.org/.

21) See http://www.aplac.org/.

22) T. Matsumoto, H. Harano, Y. Sato, H. Matsue, M. Segawa, J. Hori, A. Uritani and K. Kudo, "Development of a thermal neutron calibration field using a reactor produced neutron beam," Abst. of the $12^{\text {th }}$ International Conference on Modern Trends in Activation Analysis (MTAA-12), Tokyo, Japan, Sep. 17-21, 2007, 133.

23) Y. Oyama, "J-PARC and new era of science," Nucl. Instr. and Meth. A, 562, 548-552 (2006).

24) M. Baba, Y. Nauchi, T. Iwasaki, T. Kiyosumi, M. Yoshioka, S. Matsuyama, N. Hirakawa, T. Nakamura, Su. Tanaka, S. Meigo, H. Nakashima, Sh. Tanaka, N. Nakao, "Characterization of 40-90 $\mathrm{MeV}^{7} \mathrm{Li}(\mathrm{p}, \mathrm{n})$ Neutron Source at TIARA using a Proton Recoil Telescope and a TOF Method," Nucl. Instr. and Meth. A, 428, 454-465 (1999).

25) M. Baba, H. Okamura, M. Hagiwara, T. Itoga, S. Kamada, Y. Yahagi, E. Ibe, "Installation and application of an intense ${ }^{7} \mathrm{Li}(\mathrm{p}, \mathrm{n})$ Neutron source for $20-90 \mathrm{MeV}$ region," Radiat. Prot. Dosim., 126, 13-17 (2007). 